\title{
Pretreatment platelet count as a prognostic factor in patients with pancreatic cancer: a systematic review and meta-analysis
}

This article was published in the following Dove Press journal:

OncoTargets and Therapy

\author{
Sheng Chen ${ }^{1, *}$ \\ Ning $\mathrm{Na}^{2, *}$ \\ Zhixiang Jian' \\ 'Department of General Surgery, \\ Guangdong General Hospital, \\ Guangdong Academy of Medical \\ Sciences, ${ }^{2}$ Department of Kidney \\ Transplantation, The Third Affiliated \\ Hospital of Sun Yat-sen University, \\ Guangzhou, Guangdong, People's \\ Republic of China \\ *These authors contributed equally \\ to this work
}

Background: The relationship between platelet counts and pancreatic cancer as a prognostic factor has been reported in many studies. We aimed to evaluate the prognostic value of platelet counts in predicting the prognosis of pancreatic cancer patients.

Methods: We searched PubMed, Medline, EMBASE, and Google Scholar for eligible studies up to May 2017. Information about the characteristics of the study and relevant outcomes was extracted. A meta-analysis was performed to analyze the prognostic value of platelet counts using the hazard ratio (HR) and 95\% confidence intervals (CIs).

Results: A total of 1,756 patients in 13 retrospective studies were included. The pooled HR of 1.51 (95\% CI: $1.20-1.90, P<0.001)$ showed that patients with elevated platelet counts were expected to have poor overall survival after treatment. Subgroup analysis showed that prognostic value of platelet levels was stronger in patients who received surgical resection ( $\mathrm{HR}=1.60$, 95\% CI: $1.09-2.34, P=0.02)$, followed by patients who received palliative therapy $(\mathrm{HR}=1.46$, 95\% CI: $1.03-2.06, P=0.03$ ).

Conclusion: Platelet counts could be a useful prognostic marker for pancreatic cancer. Patients with high platelet counts are expected to have poor survival.

Keywords: pancreatic adenocarcinoma, blood parameters, platelet, prognosis, evidence-based medicine

\section{Introduction}

Thrombocytosis and coagulopathy are associated with the prognosis of patients with digestive malignant tumors, including pancreatic cancer. ${ }^{1}$ Platelets are the smallest circulating blood cells that are involved in multiple links of the process of thrombus formation and development. ${ }^{2,3}$ Studies revealed that activated platelets can participate in tumor progression via multiple mechanisms. ${ }^{4}$ Platelets themselves can promote primary cancer growth by releasing different types of growth factors, chemokines, proangiogenic regulatory proteins, and proteolytic enzymes that promote tumor cell growth and invasion; ${ }^{5}$ platelets can also enhance the dissemination and implantation of cancer by assisting in the formation of platelet-tumor cell heteroaggregates. ${ }^{6}$

The platelet count is a widely used marker and can be easily acquired from complete blood cell parameters. Prognostic factors are essential for the stratification of cancer risk, medical treatment, and clinical research. Although emerging evidence supports a role for platelets in pancreatic cancer, the value of platelet counts in predicting pancreatic cancer prognosis is still controversial, and the association between platelet counts and survival in pancreatic cancer patients has not been previously reviewed. Hence, we aimed to conduct 
a systematic review and meta-analysis to reveal the value of platelet counts in predicting pancreatic cancer prognosis.

\section{Methods}

\section{Literature search and filtration strategy}

A literature search was performed in May 2017 without restriction to regions and publication types. We systematically searched PubMed, Medline, EMBASE, and Google Scholar to retrieve possible articles relevant to the topic of interest. The following MeSH terms or text words and their combinations were searched to retrieve potentially eligible studies: "blood", "hematological", "hemogram", "platelet", "pancreas", "pancreatic", “cancer”, "carcinoma", "adenocarcinoma", "tumor", "neoplasm", and "malignancy". The initial selection was performed to exclude obviously irrelevant articles and to retain potentially relevant articles about platelet or pancreatic cancer prognostic risk factors by reviewing the title and abstract by two independent investigators (SC and $\mathrm{NN}$ ). Thereafter, the full text of a study was further reviewed for eligibility if either reviewer found that the articles' title and abstract met the following criteria: 1) prospective or retrospective studies that researched the prognostic role of platelets in pancreatic cancer patients; and 2) the hazard ratios (HRs) of overall survival (OS), cancer-specific survival (CCS), or progression-free survival, along with their $95 \%$ confidence intervals (CIs) or $P$-values were available. When more than one study described a same population, the most recent or complete study was involved. Studies with the following criteria were excluded: basic research, duplicated literature, overlapping patients, studies without enough available data to obtain the HR values of outcomes, case reports, and letters. Meeting abstracts were not included due to lack of sufficient detail regarding methodology data and low quality.

\section{Data abstraction}

Two investigators ( $\mathrm{SC}$ and $\mathrm{NN}$ ) independently reviewed each eligible study using a standardized form. Information about the characteristics of the study population, details of platelet values, and relevant outcomes was recorded. For studies showing only survival curves, the study authors were contacted to obtain the original data; otherwise, the HR values were estimated by the methods described by Tierney et al. ${ }^{7}$ Disagreements between the investigators were resolved through discussion. When necessary, the third investigator (ZJ) helped to reach a consensus.

\section{Quality assessments}

Currently, there is no standard quality assessment tool for prognostic studies in systematic reviews and meta-analyses.
The quality assessment of included studies was evaluated using the "Newcastle-Ottawa Scale" for cohort studies, which consisted of three major events with eight items, for a total score of $0-9$; studies achieving scores of $\geq 6$ were deemed as being of good quality. ${ }^{36}$ The quality of each involved study was evaluated by two reviewers (SC and $\mathrm{NN}$ ) independently. Disagreements between the investigators were resolved through discussion. When necessary, the third investigator (ZJ) helped reach a consensus.

\section{Statistical analysis}

All meta-analyses were performed using Review Manager 5.3 (The Cochrane Collaboration). We assessed heterogeneity among individual studies by the Cochran $Q$ test and $I^{2}$ analysis. Any pooled estimates with $I^{2} \geq 50 \%$ were considered to have considerable heterogeneity. Pooled HRs and their 95\% CIs were calculated using a random-effects model if the heterogeneity was considerable; otherwise, a fixed-effects model was performed. A $P$-value of $<0.05$ was considered as a statistically significant difference. Additionally, a funnel plot was used to estimate potential publication bias.

\section{Results}

\section{Selection and characteristics of included studies}

As shown in the flow chart of the literature search (Figure 1), the search strategy generated 221 studies, of which 65 studies were considered of potential value, and the full texts were retrieved for detailed evaluation. In further screening, studies were excluded for the following reasons: lack of sufficient data for estimating the HR, review articles, meeting abstracts without detailed data, letters, and comments. Finally, 13 studies published between 2005 and 2017 were included in the final meta-analysis. ${ }^{8-20}$ The characteristics of the included studies are shown in Table 1. The sample size of each study ranged from 46 to 211 , and a total of 1,756 participants were involved. The studies came from the People's Republic of China ( $n=5)$, the USA ( $n=3)$, Japan $(n=2)$, the UK $(n=1)$, and Australia $(n=1)$. All studies reported OS. Most of studies chose $300 \times 10^{9} / \mathrm{L}$ as the cutoff value between high and low platelet levels. Nine of the 13 studies used multivariate analysis. The score for the quality assessment of included studies ranged from 6 to 7 .

\section{Main findings}

All studies reported the effects of pretreatment platelet values on pancreatic cancer prognosis. The synthesized HR value 


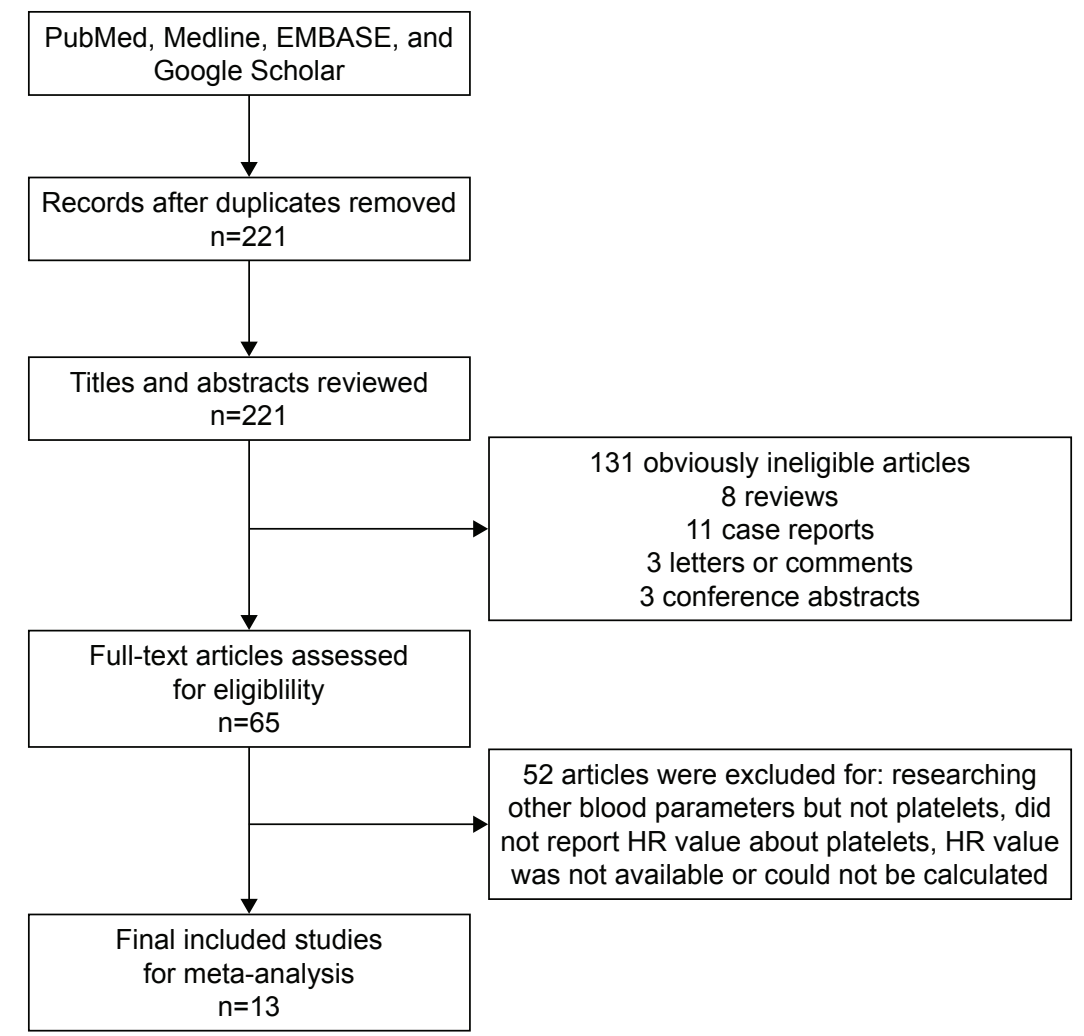

Figure I Literature screening flowchart.

Abbreviation: $\mathrm{HR}$, hazard ratio.

showed the significant superiority of a low platelet count on OS (pooled HR, 1.51, 95\% CI: $1.20-1.90, P<0.001, I^{2}=79 \%$ ) (Figure 2). Six of the included studies defined a high platelet count as $>300 \times 10^{9} / \mathrm{L} ; 9,11,12,15,19,20$ a pooled analysis of these six studies revealed that patients with pretreatment platelet counts $>300 \times 10^{9} / \mathrm{L}$ might have poorer OS than those with platelet counts $<300 \times 10^{9} / \mathrm{L}$ ( $\mathrm{HR}=1.62,95 \% \mathrm{CI}: 1.22-2.16$, $P<0.001)$. In addition, the synthesized HR for studies that used multivariate analysis was 1.78 (95\% CI: 1.39-2.30, $P<0.001){ }^{8-13,15,16,20}$

Table I Characteristics of all identified studies

\begin{tabular}{|c|c|c|c|c|c|c|c|c|c|}
\hline Study & Year & Country & $\begin{array}{l}\text { Sample } \\
\text { size }\end{array}$ & Treatment & $\begin{array}{l}\text { Sample } \\
\text { of distant } \\
\text { metastasis }\end{array}$ & $\begin{array}{l}\text { Platelet } \\
\text { cutoff } \\
\left(10^{9} / \mathrm{L}\right)\end{array}$ & $\begin{array}{l}\text { Outcome } \\
\text { measured }\end{array}$ & $\begin{array}{l}\text { HR } \\
\text { estimation }\end{array}$ & $\begin{array}{l}\text { NOS } \\
\text { score }\end{array}$ \\
\hline Miyamoto et $\mathrm{al}^{8}$ & 2017 & Japan & 95 & Surgical resection & None & 278 & OS & Multivariate & 7 \\
\hline Wang et $\mathrm{al}^{9}$ & 2015 & China & 163 & $\begin{array}{l}\text { Chemotherapy and } \\
\text { radiation therapy }\end{array}$ & None & 300 & OS & Multivariate & 7 \\
\hline Qi et al $^{10}$ & 2015 & China & 211 & Chemotherapy & $134,37.0 \%$ & 170 & OS & Multivariate & 7 \\
\hline Liu et al" & 2015 & China & 168 & $\begin{array}{l}\text { Radiation therapy or } \\
\text { radio-chemotherapy }\end{array}$ & None & 300 & OS & Multivariate & 7 \\
\hline Chadha et al ${ }^{12}$ & 2015 & USA & 199 & Chemoradiation & None & 300 & OS & Multivariate & 7 \\
\hline Asaoka et $\mathrm{al}^{13}$ & 2016 & Japan & 46 & Surgical resection & None & 235 & OS & Multivariate & 6 \\
\hline Martin et $\mathrm{al}^{14}$ & 2014 & Australia & 124 & $\begin{array}{l}\text { Chemotherapy or } \\
\text { radio-chemotherapy }\end{array}$ & $84,67.7 \%$ & 400 & OS & Univariate & 6 \\
\hline Wang et $\mathrm{al}^{15}$ & 2014 & China & 125 & Mixed & $73,58.4 \%$ & 300 & OS & Multivariate & 7 \\
\hline Miura et al ${ }^{16}$ & 2014 & Japan & 50 & Surgical resection & $2,4.0 \%$ & 150 & OS & Multivariate & 7 \\
\hline Wang et al ${ }^{17}$ & 2012 & China & 177 & Mixed & $32,18.1 \%$ & 400 & OS & Univariate & 6 \\
\hline Bhatti et $a^{18}$ & 2010 & UK & 84 & Surgical resection & None & Continuous & OS & Univariate & 6 \\
\hline Dominguez et $\mathrm{al}^{19}$ & 2008 & USA & 205 & Surgical resection & None & 300 & OS & Survival curve & 6 \\
\hline Brown et $\mathrm{a}^{20}$ & 2005 & USA & 109 & Surgical resection & None & 300 & OS & Multivariate & 7 \\
\hline
\end{tabular}

Abbreviations: HR, hazard ratio; NOS, Newcastle-Ottawa Scale; OS, overall survival. 


\begin{tabular}{|c|c|c|c|c|}
\hline $\begin{array}{l}\text { Study or } \\
\text { subgroup }\end{array}$ & $\log [\mathrm{HR}]$ & SE & $\begin{array}{l}\text { Weight } \\
(\%)\end{array}$ & $\begin{array}{l}\text { HR IV, random, } \\
95 \% \mathrm{Cl}\end{array}$ \\
\hline Brown et $\mathrm{al}^{20}$ & 0.7315 & 0.2718 & 7.5 & $2.08(1.22,3.54)$ \\
\hline Dominguez et al ${ }^{19}$ & 0.063 & 0.1634 & 10.1 & $1.07(0.77,1.47)$ \\
\hline Bhatti et al ${ }^{18}$ & 0 & 0.0026 & 12.5 & $1.00(0.99,1.01)$ \\
\hline Wang et al ${ }^{17}$ & 0.6831 & 0.3889 & 5.3 & $1.98(0.92,4.24)$ \\
\hline Miura et al ${ }^{16}$ & 2.0059 & 0.7025 & 2.3 & $7.43(1.88,29.45)$ \\
\hline Wang et $\mathrm{al}^{15}$ & 0.2677 & 0.3035 & 6.8 & $1.31(0.72,2.37)$ \\
\hline Martin et $\mathrm{al}^{14}$ & -0.0943 & 0.2387 & 8.3 & $0.91(0.57,1.45)$ \\
\hline Qi et al ${ }^{10}$ & 0.0917 & 0.1638 & 10.1 & $1.10(0.80,1.51)$ \\
\hline Wang et $\mathrm{al}^{9}$ & 0.392 & 0.2538 & 7.9 & $1.48(0.90,2.43)$ \\
\hline Chadha et al ${ }^{12}$ & 0.7793 & 0.2223 & 8.7 & $2.18(1.41,3.37)$ \\
\hline Liu et $\mathrm{al}^{11}$ & 0.802 & 0.2753 & 7.4 & $2.23(1.30,3.83)$ \\
\hline Asaoka et $\mathrm{al}^{13}$ & 0.7227 & 0.4638 & 4.2 & $2.06(0.83,5.11)$ \\
\hline Miyamoto et $\mathrm{al}^{8}$ & 0.7006 & 0.2129 & 8.9 & $2.01(1.33,3.06)$ \\
\hline Total $(95 \% \mathrm{Cl})$ & & & 100 & $1.51(1.20,1.90)$ \\
\hline
\end{tabular}

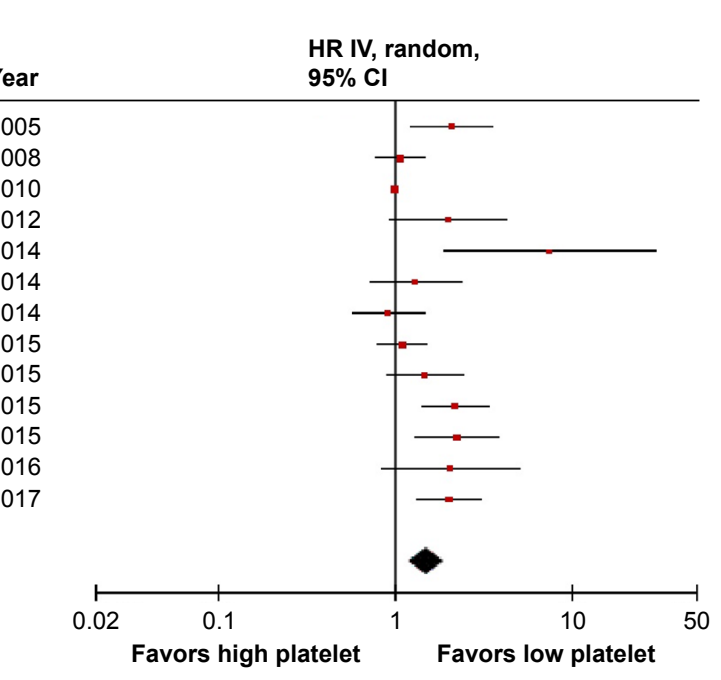

Figure 2 Forest plot and meta-analysis for the relationship between pretreatment platelet counts and OS in patients with pancreatic cancer.

Note: The results are presented as individual and combined $\mathrm{HRs}$ and $95 \% \mathrm{Cl}$.

Abbreviations: $\mathrm{Cl}$, confidence interval; $\mathrm{HRs}$, hazard ratios; OS, overall survival; IV, inverse variance.

\section{Subgroup analysis}

Figure 3 shows the subgroup analysis based on stages of pancreatic cancer. Studies were divided into three subgroups according to the patient characteristics they enrolled: 1) studies enrolled only patients with resectable lesions; ${ }^{8,13,16,18-20} 2$ ) studies enrolled only patients with unresectable lesions who were locally advanced and/or metastatic and subsequently received palliative therapy (chemotherapy, radiotherapy,

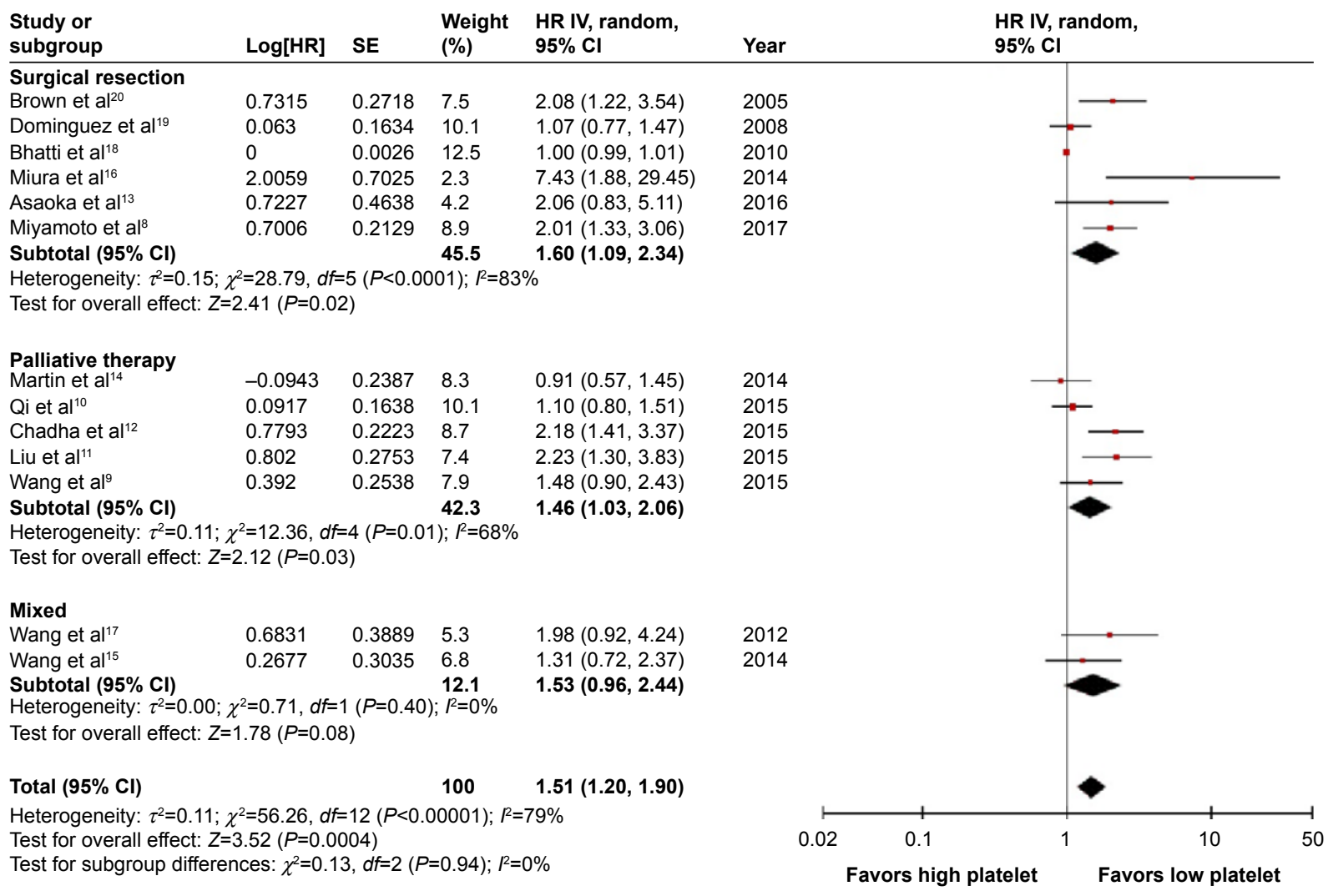

Figure 3 Subgroup analysis of the HRs of OS by types of cancer population and treatment.

Notes: Surgical resection: studies involved only cases with resectable lesions who received surgery; palliative therapy: studies involved unresectable cases who received chemotherapy and/or radiotherapy only; mixed: studies involved both resectable cases and unresectable cases.

Abbreviations: $\mathrm{Cl}$, confidence interval; HRs, hazard ratios; OS, overall survival; SE, standard error; IV, inverse variance. 


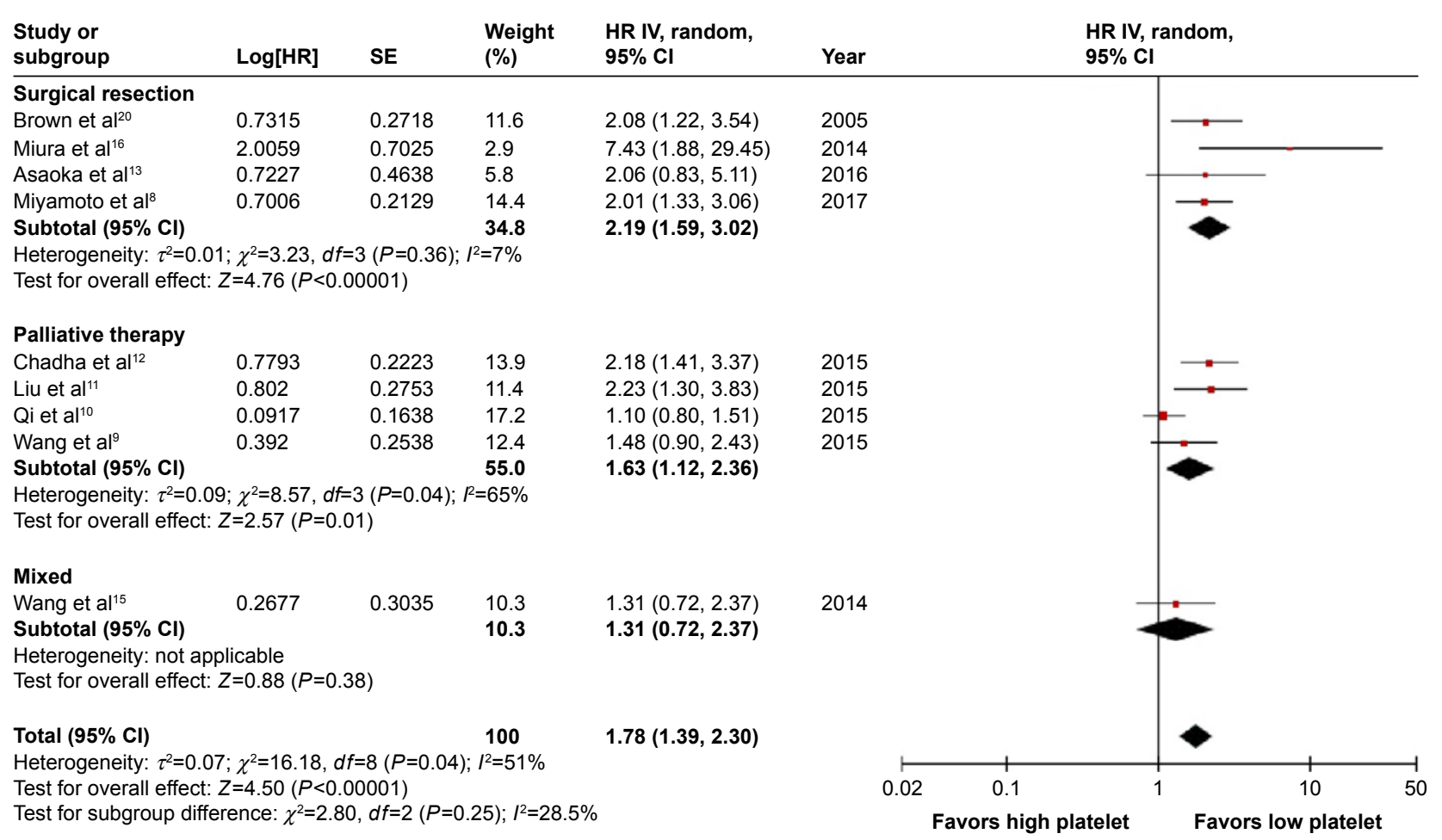

Figure 4 Subgroup analysis by types of cancer population and treatment pooling studies used multivariate analysis.

Notes: Surgical resection: studies involved only cases with resectable lesions that received surgery; palliative therapy: studies involved unresectable cases that received chemotherapy and/or radiotherapy only; mixed: studies involved both resectable cases and unresectable cases. The results are presented as individual and combined $\mathrm{HRs}$ for OS and the $95 \% \mathrm{Cl}$.

Abbreviations: $\mathrm{Cl}$, confidence interval; HRs, hazard ratios; OS, overall survival; SE, standard error; IV, inverse variance.

or chemoradiotherapy); ${ }^{9-12,14}$ and 3) studies included both resectable cases and unresectable cases. ${ }^{15,17}$ The results showed that the prognostic value of platelet count was best for resectable cases ( $\mathrm{HR}=1.60,95 \% \mathrm{CI}: 1.09-2.34, P=0.02)$, followed by unresectable patients $(\mathrm{HR}=1.46,95 \% \mathrm{CI}$ : 1.03-2.06, $P=0.03$ ).

The same subgroup analysis was also performed in studies that used multivariate analysis (Figure 4), and we found that the HR from four studies that only included resectable cases was 2.19 (95\% CI: $1.59-3.02, P<0.001, I^{2}=7 \%$ ); the low $I^{2}$ value revealed that only minor heterogeneity existed across the studies in this subgroup. The HR synthesized from data from studies only involving advanced cases was 1.63 (95\% CI: $1.12-2.36, P=0.01, I^{2}=65 \%$ ).

\section{Publication bias}

A funnel plot (Figure 5) was constructed, and it revealed a potential publication bias in this meta-analysis.

\section{Discussion}

It is now widely regarded that outcomes in cancer patients are dependent on not only the tumor characteristics but also several host-related factors. ${ }^{21}$ Platelets serve various roles in physiological pathways, including coagulation and inflammation. ${ }^{22,23}$ Abnormal platelet levels have been found in various types of solid tumors, and some studies have suggested that elevated platelet levels are correlated with disease progression, metastasis, and poor patient prognosis. ${ }^{24,25}$ However, although pancreatic cancer is traditionally associated with hypercoagulable states, the prognostic significance of pretreatment platelet counts in predicting pancreatic

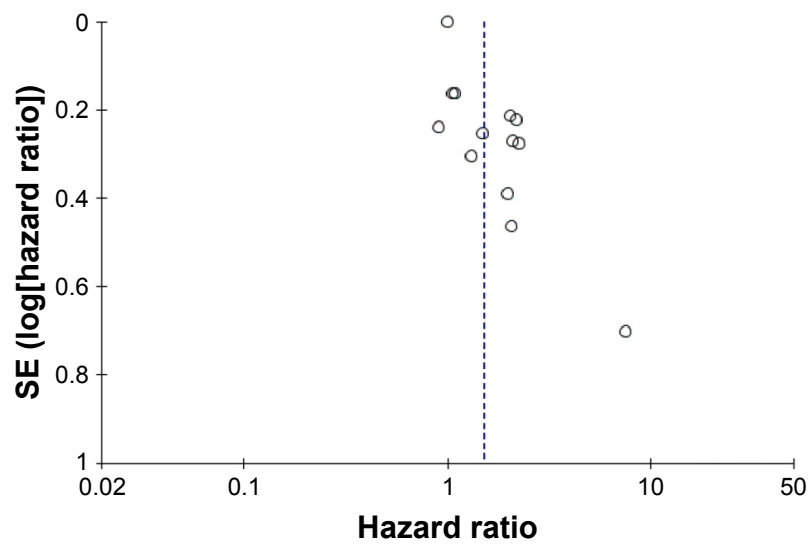

Figure 5 Funnel plots based on the value of platelets in predicting OS in patients with pancreatic cancer.

Abbreviations: OS, overall survival; SE, standard error. 
cancer outcome remains controversial. Based on our metaanalysis, we found evidence that an elevated treatment platelet level is associated with poor outcome in patients with pancreatic cancer.

The mechanisms by which platelets contribute to cancer progression remain not completely answered. The tumor itself may stimulate thrombocytopoiesis by secreting cytokines. ${ }^{26}$ Tumor cells can also induce platelet activation through a variety of pathways, such as enhancing the expression of surface integrins and selectins and the secretion of granules, which amplify platelet aggregation. ${ }^{27-29}$ Activated platelets, in turn, promote primary cancer cell growth and invasion by releasing a large number of growth factors, including angiogenic cytokines, mitogenic proteins, and growth factors. ${ }^{6}$ Platelets can adhere to tumor cells through adhesion receptors such as GPIIb/IIIa and P-selectin. ${ }^{30,31}$ The formation of heteroaggregates between tumor cells and platelets is enhanced by this type of platelet-tumor cell interaction. ${ }^{27,32,33}$ According to our present understanding, tumor cells in circulating blood stream face physical damage and immunological cytotoxicity that can potentially inhibit tumor metastasis and implantation, but heteroaggregates protect cancer cells from these potential damages..$^{34,35}$

The majority of the included studies enrolled only patients with resectable pancreatic cancer, and the remaining studies included locally advanced and/or metastatic lesions that then received adjuvant therapy only. In addition to confirming the association between platelet counts and the prognosis of pancreatic cancer patients, our subgroup analysis revealed that the prognostic efficacy of platelet counts seems to be stronger in cases with resectable tumors than in those who could only receive adjuvant therapy. Studies have suggested that aggressive pancreatic cancer cells may disseminate to the bone marrow, and platelet counts may decrease in advanced pancreatic cancer patients; additionally, locally advanced cancer cases are usually accompanied by thrombocytopenia caused by splenic vein occlusion. ${ }^{9}$ Therefore, pretreatment platelet levels might be affected by many more factors in end-stage pancreatic cancer patients than in resectable cases. However, the real reason why platelet counts show better prognostic value in resectable cases remains unanswered.

There are several limitations in our study. First, all of the included studies were retrospective. In observational studies, selection bias is impossible to avoid, although a multivariate analysis can control the confounding factors to a certain extent. Second, the platelet counts could be affected by multiple factors, especially undetected diseases, such as chronic infection, hematological disease, and peripheral arterial disease. Most of the included studies did not report CCS, which is an essential outcome for cancer patients. Third, we noted that all studies used the dichotomous platelet counts to determine the prognostic value and most of them chose the normal hemogram platelet values as the cutoff value. Thus, we recommend using a continuous platelet counts variable rather than a categorical variable in future studies.

\section{Conclusion}

This meta-analysis is the first to evaluate the platelet count as a prognostic marker for patients with pancreatic cancer, and the pooled results suggest that the pretreatment platelet count is closely correlated with the prognosis of patients with pancreatic cancer. However, due to the limitations of the included studies, more multi-center prospective cohorts need to be conducted to validate the role and exact cutoff value for platelet counts in predicting the prognosis of pancreatic cancer.

\section{Acknowledgments}

This work was supported by grants from the Science Foundation of Guangdong Province, People's Republic of China (No 2014A030310073) and the Guangzhou Science and Technology Plan of Scientific Research Projects, People's Republic of China (No 201510010286).

\section{Disclosure}

The authors report no conflicts of interest in this work.

\section{References}

1. Baranyai Z, Josa V, Toth A, et al. Paraneoplastic thrombocytosis in gastrointestinal cancer. Platelets. 2016;27(4):269-275.

2. Davi G, Patrono C. Platelet activation and atherothrombosis. $N$ Engl $J$ Med. 2007;357(24):2482-2494.

3. Falanga A, Russo L, Milesi V. The coagulopathy of cancer. Curr Opin Hematol. 2014;21(5):423-429.

4. Nash GF, Turner LF, Scully MF, Kakkar AK. Platelets and cancer. Lancet Oncol. 2002;3(7):425-430

5. Toi M, Atiqur Rahman M, Bando H, Chow LW. Thymidine phosphorylase (platelet-derived endothelial-cell growth factor) in cancer biology and treatment. Lancet Oncol. 2005;6(3):158-166.

6. Tesfamariam B. Involvement of platelets in tumor cell metastasis. Pharmacol Ther. 2016;157:112-119.

7. Tierney JF, Stewart LA, Ghersi D, Burdett S, Sydes MR. Practical methods for incorporating summary time-to-event data into meta-analysis. Trials. 2007;8:16.

8. Miyamoto R, Oda T, Hashimoto S, et al. Platelet x CRP multiplier value as an indicator of poor prognosis in patients with resectable pancreatic cancer. Pancreas. 2017;46(1):35-41.

9. Wang L, Sheng L, Liu P. The independent association of platelet parameters with overall survival in pancreatic adenocarcinoma receiving intensity-modulated radiation therapy. Int J Clin Exp Med. 2015;8(11): 21215-21221. 
10. Qi Q, Geng Y, Sun M, Wang P, Chen Z. Clinical implications of systemic inflammatory response markers as independent prognostic factors for advanced pancreatic cancer. Pancreatology. 2015;15(2):145-150.

11. Liu P, Zhu Y, Liu L. Elevated pretreatment plasma D-dimer levels and platelet counts predict poor prognosis in pancreatic adenocarcinoma. Onco Targets Ther. 2015;8:1335-1340.

12. Chadha AS, Kocak-Uzel E, Das P, et al. Paraneoplastic thrombocytosis independently predicts poor prognosis in patients with locally advanced pancreatic cancer. Acta Oncol. 2015;54(7):971-978.

13. Asaoka T, Miyamoto A, Maeda S, et al. Prognostic impact of preoperative NLR and CA19-9 in pancreatic cancer. Pancreatology. 2016; 16(3):434-440.

14. Martin HL, Ohara K, Kiberu A, Van Hagen T, Davidson A, Khattak MA. Prognostic value of systemic inflammation-based markers in advanced pancreatic cancer. Intern Med J. 2014;44(7):676-682.

15. Wang H, Gao J, Bai M, et al. The pretreatment platelet and plasma fibrinogen level correlate with tumor progression and metastasis in patients with pancreatic cancer. Platelets. 2014;25(5):382-387.

16. Miura T, Hirano S, Nakamura T, et al. A new preoperative prognostic scoring system to predict prognosis in patients with locally advanced pancreatic body cancer who undergo distal pancreatectomy with en bloc celiac axis resection: a retrospective cohort study. Surgery. 2014; 155(3):457-467

17. Wang DS, Luo HY, Qiu MZ, et al. Comparison of the prognostic values of various inflammation based factors in patients with pancreatic cancer. Med Oncol. 2012;29(5):3092-3100.

18. Bhatti I, Peacock O, Lloyd G, Larvin M, Hall RI. Preoperative hematologic markers as independent predictors of prognosis in resected pancreatic ductal adenocarcinoma: neutrophil-lymphocyte versus platelet-lymphocyte ratio. Am J Surg. 2010;200(2):197-203.

19. Dominguez I, Crippa S, Thayer SP, et al. Preoperative platelet count and survival prognosis in resected pancreatic ductal adenocarcinoma. World J Surg. 2008;32(6):1051-1056.

20. Brown KM, Domin C, Aranha GV, Yong S, Shoup M. Increased preoperative platelet count is associated with decreased survival after resection for adenocarcinoma of the pancreas. Am J Surg. 2005; 189(3):278-282.

21. Hanahan D, Weinberg RA. Hallmarks of cancer: the next generation. Cell. 2011;144(5):646-674.

22. Gawaz M, Langer H, May AE. Platelets in inflammation and atherogenesis. J Clin Invest. 2005;115(12):3378-3384.
23. Franco AT, Corken A, Ware J. Platelets at the interface of thrombosis, inflammation, and cancer. Blood. 2015;126(5):582-588.

24. Mezouar S, Frere C, Darbousset R, et al. Role of platelets in cancer and cancer-associated thrombosis: experimental and clinical evidences. Thromb Res. 2016;139:65-76.

25. Meikle CK, Kelly CA, Garg P, Wuescher LM, Ali RA, Worth RG. Cancer and thrombosis: the platelet perspective. Front Cell Dev Biol. 2016;4:147.

26. Sousou T, Khorana AA. New insights into cancer-associated thrombosis. Arterioscler Thromb Vasc Biol. 2009;29(3):316-320.

27. Medina C, Jurasz P, Santos-Martinez MJ, et al. Platelet aggregationinduced by caco-2 cells: regulation by matrix metalloproteinase- 2 and adenosine diphosphate. J Pharmacol Exp Ther. 2006;317(2):739-745.

28. Erpenbeck L, Schon MP. Deadly allies: the fatal interplay between platelets and metastasizing cancer cells. Blood. 2010;115(17):3427-3436.

29. Nierodzik ML, Karpatkin S. Thrombin induces tumor growth, metastasis, and angiogenesis: evidence for a thrombin-regulated dormant tumor phenotype. Cancer Cell. 2006;10(5):355-362.

30. Bakewell SJ, Nestor P, Prasad S, et al. Platelet and osteoclast beta3 integrins are critical for bone metastasis. Proc Natl Acad Sci U S A. 2003; 100(24):14205-14210.

31. Amirkhosravi A, Mousa SA, Amaya M, et al. Inhibition of tumor cellinduced platelet aggregation and lung metastasis by the oral GpIIb/IIIa antagonist XV454. Thromb Haemost. 2003;90(3):549-554.

32. Lonsdorf AS, Kramer BF, Fahrleitner M, et al. Engagement of alphaIIbbeta3 (GPIIb/IIIa) with alphanubeta3 integrin mediates interaction of melanoma cells with platelets: a connection to hematogenous metastasis. J Biol Chem. 2012;287(3):2168-2178.

33. Gay LJ, Felding-Habermann B. Contribution of platelets to tumour metastasis. Nat Rev Cancer. 2011;11(2):123-134.

34. Jain S, Zuka M, Liu J, et al. Platelet glycoprotein Ib alpha supports experimental lung metastasis. Proc Natl Acad Sci US A. 2007;104(21): 9024-9028.

35. Sierko E, Wojtukiewicz MZ. Inhibition of platelet function: does it offer a chance of better cancer progression control? Semin Thromb Hemost 2007;33(7):712-721.

36. Wells GA, Shea B, O'Connell D, et al. The Newcastle-Ottawa Scale (NOS) for assessing the quality of nonrandomised studies in metaanalyses. Ottawa, ON: The Ottawa Hospital Research Institute; 2008 Available from: http://www.ohri.ca/programs/clinical_epidemiology/ oxford.asp. Accessed November 24, 2017.
OncoTargets and Therapy

\section{Publish your work in this journal}

OncoTargets and Therapy is an international, peer-reviewed, open access journal focusing on the pathological basis of all cancers, potential targets for therapy and treatment protocols employed to improve the management of cancer patients. The journal also focuses on the impact of management programs and new therapeutic agents and protocols on

\section{Dovepress}

patient perspectives such as quality of life, adherence and satisfaction. The manuscript management system is completely online and includes a very quick and fair peer-review system, which is all easy to use. Visit http://www.dovepress.com/testimonials.php to read real quotes from published authors. 